\title{
EVALUASI KEBIJAKAN PERSEDIAAN BAHAN BAKU KANTONG SEMEN UNTUK MENGURANGI BIAYA PERSEDIAAN (Studi Kasus: PT. SOLUSI BANGUN INDONESIA TBK).
}

\section{EVALUATION OF INVENTORY POLICY IN CEMENT BAGS MATERIAL FOR DECREASING INVENTORY COST (Case Study: PT. SOLUSI BANGUN INDONESIA TBK).}

Zahra Zayyina Yustisia Arif', Iwan Sukarno²

1,2) Program Studi Teknik Logistik Universitas Pertamina, Jakarta Selatan, 12220, Indonesia

\begin{tabular}{|c|c|}
\hline ARTICLE INFORMATION & A B S T R A C T \\
\hline $\begin{array}{l}\text { Article history: } \\
\text { Received: July } 08,20 \\
\text { Revised: October } 15,20 \\
\text { Accepted: November 16, } 20\end{array}$ & $\begin{array}{l}\text { This study aims to evaluate company policy in determining raw material } \\
\text { ordering rates which are then compared with the EOQ, POQ, and Min-Max } \\
\text { methods. This research uses a quantitive case study method using data } \\
\text { obtained from the company. Forecasting is done using WinQSB and MAD, } \\
\text { MSE and MAPE software for forecasting accuracy. Based on data } \\
\text { processing, the data shows the horizontal pattern and the chosen } \\
\text { forecasting method is the Simple Average method. Research shows the }\end{array}$ \\
\hline $\begin{array}{l}\text { Keywords: } \\
\text { EOQ } \\
\text { POQ } \\
\text { Min - Max } \\
\text { Forecasting }\end{array}$ & $\begin{array}{l}\text { EOQ method has an order quantity of } 1192 \text { units / order with an order } \\
\text { frequency of } 11 \text { times a year and has the smallest total inventory cost of } \\
\text { the three methods compared which is Rp } 269,520,852,781 \text { or almost } 50 \% \\
\text { lower than the total costs incurred by the company using the current } \\
\text { method. ROP point has a value of } 3395 \text { units with a safety stock value of } \\
106 \text { units. }\end{array}$ \\
\hline
\end{tabular}

\section{A B S T R A K}

Penelitian ini bertujuan untuk mengevaluasi kebijakan perusahaan dalam menentukan tingkat pemesanan bahan baku yang kemudian dibandingkan dengan metode EOQ, POQ dan Min-Max. Penelitian ini menggunakan metode studi kasus kuantitatif dengan menggunakan data yang diperoleh dari perusahaan. Peramalan dilakukan menggunakan perangkat lunak WinQSB dan MAD, MSE dan MAPE untuk akurasi peramalan. Berdasarkan pengolahan data, data menunjukkan pola horizontal dan metode peramalan yang dipilih adalah metode Simple Average. Penelitian ini menunjukkan metode EOQ memiliki jumlah pesanan 1192 unit pesanan dengan frekuensi pemesanan 11 kali setahun dan memiliki total biaya persediaan terkecil dari ketiga metode yang dibandingkan yaitu $\mathrm{Rp}$ 269.520 .852 atau hampir $50 \%$ lebih rendah dari total biaya yang dikeluarkan oleh perusahaan dengan metode saat ini. Titik ROP memiliki nilai 3395 unit dengan nilai stok pengaman 106 unit.

This is an open access article under the $\underline{\mathrm{CC}-\mathrm{BY}}$ license.

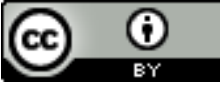




\section{PENDAHULUAN}

Kebutuhan perusahaan terhadap bahan baku kantong semen berbanding lurus terhadap permintaan semen di Indonesia. Berangkat dari data permintaan semen selama 10 tahun terakhir yang dilansir dari Asosiasi Semen Indonesia, permintaan terhadap semen cenderung mengalami kenaikan setiap tahunnya.(Gambar 1$)$.

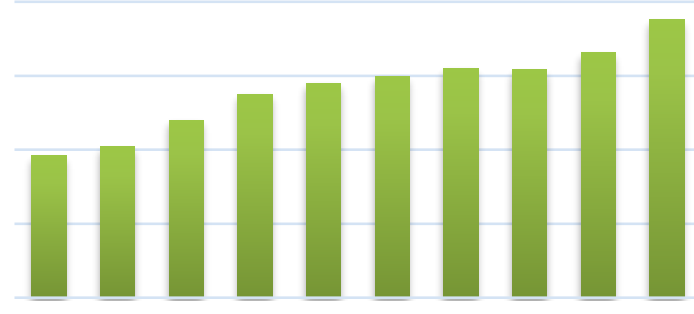

2009201020112012201320142015201620172018

Gambar 1. Permintaan Semen di Indonesia $(2009-2018)$

Ditinjau dari data permintaan di tahun 2018, permintaan untuk industri perumahan tercatat cukup tinggi dilihat dari realisasi konsumsi tahun 2018 untuk semen bag yang memiliki persentase sebesar $73 \%$ dan sisanya sebesar $27 \%$ yang merepresentasikan kebutuhan untuk proyek dan infrastruktur [1]. Tingginya permintaan semen bag berbanding lurus terhadap kebutuhan kantong semen yang diproduksi sehingga keberadaan bahan baku kantong menjadi sangat penting.

PT Solusi Bangun Indonesia yang kemudian disebut sebagai PT. SBI merupakan perusahaan produsen semen yang memiliki empat pabrik yang berada di Jawa dan Aceh yakni di Narogong, Cilacap, Tuban dan Lhoknga. Ketiga pabrik di Pulau Jawa memproduksi semen dengan kapasitas yang berbeda - beda. Dalam aktivitas bisnisnya, PT. SBI memproduksi kantong semen sendiri di bag plant Narogong dan Cilacap. Persediaan pengaman yang dimiliki oleh perusahaan saat ini adalah sebesar 5000 ton kertas dalam bentuk roll. Masing - masing roll memiliki berat lebih kurang satu ton.

Saat ini, perusahaan menggunakan bahan kantong semen (paper bag) yang dipesan dari Swedia. Proses impor kertas kantong ini memerlukan waktu yang relatif lama yakni kurang lebih selama tiga bulan. Hal ini menjadikan perencanaan stok bahan baku kertas kantong harus mampu memenuhi demand di masa - masa lead time selama tiga bulan agar terhindar dari resiko stock out. Kertas karton yang diimpor dari
Swedia datang dalam bentuk roll seberat 1 ton yang akan disimpan di dalam gudang plan Narogong berkapasitas 3400 ton. Pemenuhan bahan baku kantong semen menjadi fokus utama dalam penelitian ini sehingga tujuan utama adalah mengevaluasi kebijakan persediaan perusahaan terkait safety stock dalam gudang penyimpanan. Saat ini perusahaan belum menggunakan metode apapun dalam penentuan kuantitas pesanan maupun tingkat safety stock nya.

Hasil investigasi awal terhadap kebijakan perusahan yang saat ini digunakan adalah (1) cara pemesanan yakni kuantitas pemesanan tetap, (2) lead time yang digunakan tetap yaitu 3 bulan, (3) harga barang yang dibeli relatif stabil, (4) biaya penyimpanan diasumsikan tetap, (5) biaya pemesanan konstan, sehingga pendekatan awal yang digunakan adalah dengan mengggunakan metode $\mathrm{EOQ}$.

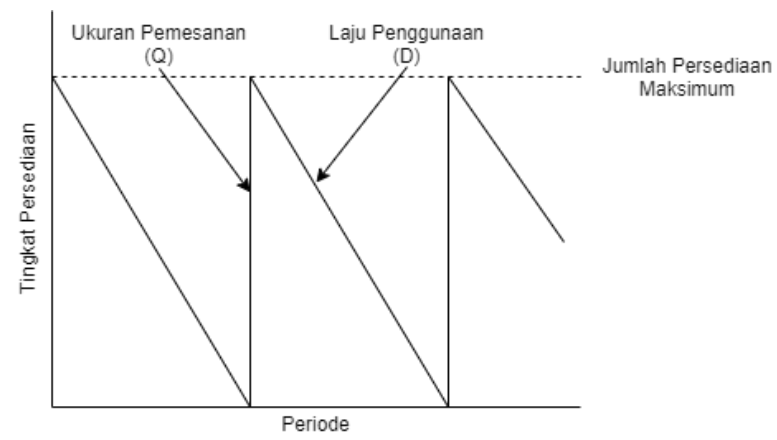

Gambar 2. Model EOQ

Oleh sebab itu, penelitian ini mencoba melakukan evaluasi terhadap kebijakan perusahaan yang saat ini dijalankan serta membandingkan dengan beberapa kebijakan persediaan seperti $P O Q$ dan Min-Max. Penggunaan sistem POQ dalam perhitungan bertujuan untuk challenge sistem perusahaan dimana metode $P O Q$ bertentangan dengan siklus metode $E O Q$ yakni kuantitas pesan menyesuaikan dengan kapasitas maksimal sehingga kuantitas berbeda - beda dalam sekali pesan, namun waktu pemesanan dilakukan secara seragam.

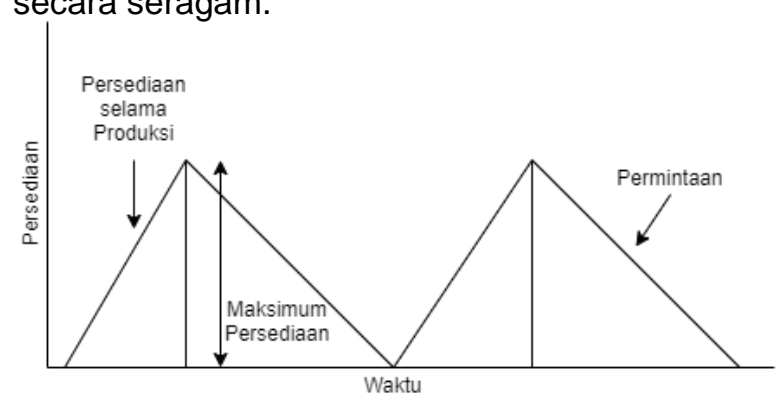

Gambar 3. Model POQ 
Prima dan Annise [2] melakukan penelitian terkait pengendalian persediaan pozzolan menggunakan metode $E O Q$ dan $P O Q$ yang bertujuan untuk membandingkan dengan metode yang diterapkan oleh perusahaan. Pendekatan ke-tiga yang digunakan adalah metode min - max sebagai metode yang paling banyak digunakan oleh perusahaan-perusahaan. Alynardiana dan Saifi [3] melakukan penelitian perencanaan persediaan bahan baku di perusahaan induk PT. SBI yakni Semen Indonesia di Pabrik Tuban dengan metode EOQ yang mana sistem pada pabrik tersebut menggunakan metode min - max. Mail, dkk [4] melakukan penelitian tentang pengendalian persediaan bahan baku menggunakan metode min - max yang bertujuan untuk menghindari kelebihan dan kekurangan bahan baku. Gani dan Saputri [5] menganalisis peramalan dan pengendalian persediaan bahan baku menggunakan metode EOQ pada optimalisasi kayu untuk membantu perusahaan menentukan kuantitas persediaan. Rizky, dkk [6] menganalisa perbandingan metode $E O Q, P O Q$ dan Min - Max dalam pengendalian persediaan bahan baku di PT Sidomuncul Pupuk Nusantara yang bertujuan untuk mencari biaya persediaan bahan baku yang minimal dan mencari kuantitas kuantitas pemesanan dan frekuensi pemesanan yang optimum. Penelitian terbaru dari Evitha dan Ma'ruf [7] menunjukkan adanya pengaruh positif antara variabel EOQ terhadap variabel pengendalian persediaan bahan baku produksi. Fokus penelitian ini adalah mengevaluasi kebijakan perusahaan dalam mengatur persediaan bahan baku kantung semen yang dilakukan dengan membandingkan kebijakan tersebut dengan beberapa metode yang telah digunakan pada penelitian - penelitian sebelumnya seperti EOQ, $\mathrm{POQ}$ dan Min - Max. Evaluasi kebijakan persediaan berpengaruh terhadap biaya persediaan yang harus dikeluarkan oleh perusahaan, sehingga hasil dari penelitian ini diharapkan dapat menjadi pertimbangan bagi perusahaan dalam mengambil keputusan terkait biaya persediaan seperti penentuan kuantitas pemesanan agar dapat meminimasi biaya pemesanan dan biaya simpan persediaan bahan baku.

\section{METODE PENELITIAN}

Penelitian ini terbagi ke beberapa tahapan yakni tahap satu penentuan lokasi penelitian, tahap kedua definisi masalah, tahap ketiga pengumpulan data, tahap keempat model matematika dan tahap kelima setting experiment.

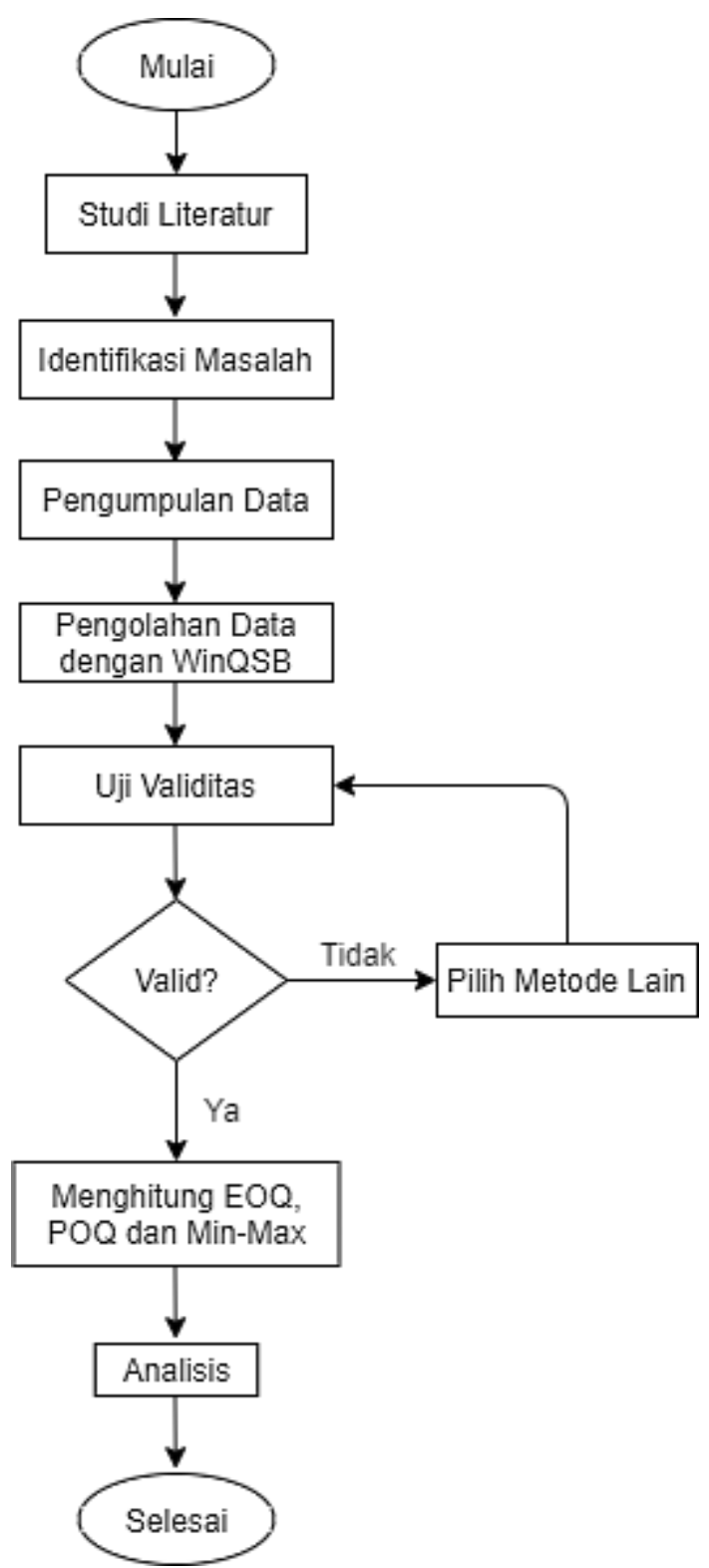

Gambar 4. Diagram Alir Penelitian

\subsection{Lokasi Penelitian}

Lokasi penelitian dilakukan di PT Solusi Bangun Indonesia Pabrik Narogong yang berada di Jalan Narogong KM.7 Kembang Kuning, Kecamatan Klapanunggal, Bogor, Jawa Barat.

\subsection{Definisi Masalah}

Permasalahan yang muncul adalah perusahaan belum menggunakan metode apapun dalam penentuan kuantitas pesan sehingga sejauh ini masih menggunakan metode yang berdasarkan pengalaman perusahaan. Hal ini mengakibatkan tingkat safety stock dianggap terlalu tinggi. Penelitian ini diasumsikan harga barang baku tetap selama satu tahun periode, data yang digunakan merupakan data aktual perusahaan, 
dan perhitungan mempertimbangkan kapasitas gudang.

\subsection{Pengumpulan Data}

Data yang diperlukan dalam penelitian ini adalah data aktual selama 12 periode penggunaan roll bags pada tahun sebelumnya untuk digunakan sebagai acuan peramalan.

\subsection{Model Matematika}

Penyelesaian permasalahan pada penelitian ini menggunakan beberapa pendekatan yang dirumuskan sebagai berikut:

1. Penghitungan $\mathrm{EOQ}$

$$
\begin{aligned}
& \mathrm{Q}^{*}=\sqrt{\frac{2 \mathrm{DS}}{\mathrm{H}}} \\
& \mathrm{F} \quad=\frac{\mathrm{D}}{\mathrm{Q}^{*}} \\
& \mathrm{TIC} \quad=\frac{\mathrm{D}}{\mathrm{Q} *} \mathrm{~S}+\frac{\mathrm{Q} *}{2} \mathrm{H}
\end{aligned}
$$

2. Penghitungan Standar Deviasi dan Safety Stock (SS)

$$
\begin{aligned}
& \sigma \quad=\sqrt{\frac{\sum_{\mathrm{i}=0}^{\mathrm{n}}(\mathrm{X}-\mathrm{x})^{2}}{n}} \\
& S S=\mathrm{Z} \sigma
\end{aligned}
$$

3. Penghitungan $\mathrm{POQ}$

$$
\begin{aligned}
& \mathrm{POQ}=\sqrt{\frac{2 S}{D H}} \\
& \mathrm{Q}=\frac{\mathrm{D}}{\mathrm{F}} \\
& \mathrm{TIC}
\end{aligned}
$$

4. Penghitungan Min - Max

$$
\begin{aligned}
& S S=(M-K) L T \\
& \text { Min }=(K \times L T)+S S \\
& \text { Max }=2(K \times L T) \\
& Q=\text { Max }- \text { Min }
\end{aligned}
$$

\subsection{Setting Experiment}

Uji coba peramalan menggunakan software WinQSB (Quantitative System for Business) versi 2.00 for Windows dengan Forecasting and Linear
Regression versi 1.00. Software ini dapat membantu menyelesaikan berbagai jenis permasalahan yang menyangkut manajemen sains [8]. Penelitian ini menggunakan WinQSB dalam penyelesaian operasi hitung peramalan dengan berbagai jenis metode pendekatan.

\section{HASIL DAN PEMBAHASAN}

Berikut merupakan data historis dari penggunaan bahan baku kantong semen pada tahun 2018 . Data historis diperoleh melalui sistem SAP milik perusahaan, seperti yang terlihat pada Gambar 5.

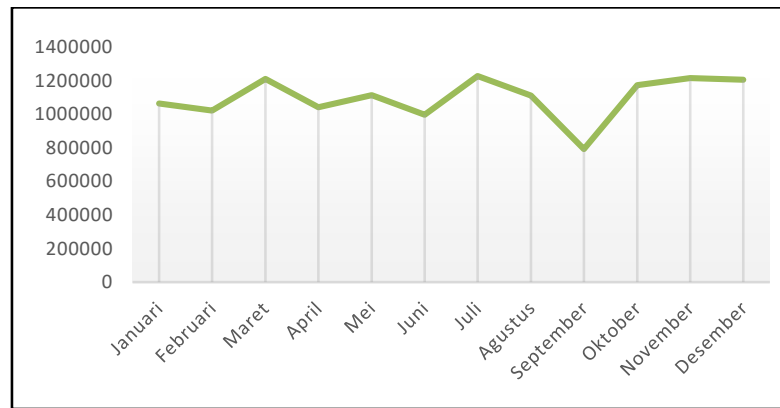

Gambar 5. Pemakaian Roll Tahun 2018

Gambar di atas menunjukkan bahwa pola data historis adalah pola data horizontal atau cenderung konstan. Metode-metode peramalan yang dapat digunakan untuk pola data horizontal antara lain adalah Simple Average (SA), Moving Average (MA), Weighted Moving Average (WMA), dan Smoothing Exponential Smoothing (SES). Hasil penghitungan peramalan menggunakan software WinQSB adalah sebagai berikut:

Tabel 1. Hasil Peramalan WinQSB

\begin{tabular}{lcccc}
\hline Metode & MAD & MSE & MAPE & K \\
\hline SA & 111415.3 & 1.85 & 10.75 & \\
MA & 129213.9 & 2.50 & 1.23 & 3MA \\
WMA & 129213.9 & 2.50 & 1.23 & 3WMA \\
SES & 112332.3 & 1.90 & 10.82 & $\alpha=0.2$ \\
\hline
\end{tabular}

Menurut Hadiguna [9] akurasi peramalan yang bermutu apabila hasil prakiraan mempunyai nilai kesalahan yang sangat kecil. Pemeriksaan hasil prakiraan sangat penting karena fungsi dan peran prakiraan sebagai informasi awal dalam perencanaan. Berdasarkan nilai MAD, MSE dan MAPE dapat dilihat metode SA memiliki nilai yang terkecil. Metode SA menjadi metode terpilih yang kemudian diuji validitasnya menggunakan peta moving range. 


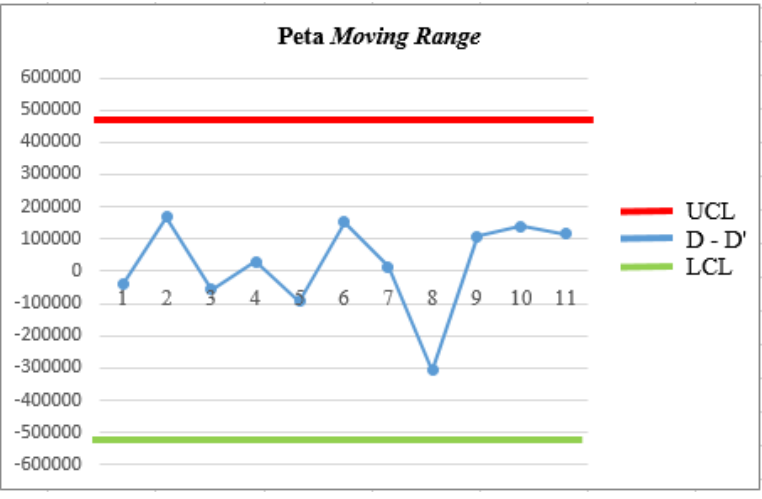

Gambar 6. Peta Moving Range

Hasil peramalan dengan pendekatan SA berada dalam rentang limit yakni berada di bawah garis merah dan berada di tas garis hijau sehingga data dianggap valid dan dapat digunakan.

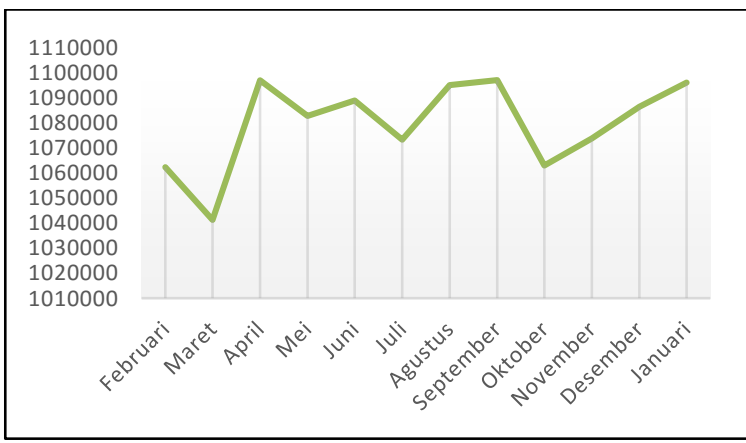

Gambar 7. Hasil Peramalan Metode SA

Peramalan dengan metode SA selanjutnya digunakan sebagai acuan penghitungan metode EOQ, POQ dan Min - Max. Metode - metode tersebut kemudian dibandingkan dengan model yang digunakan oleh perusahaan. Dari hasil perhitungan menggunakan 3 (tiga) pendekatan yang telah dijelaskan pada bagian sebelumnya dapat dilihat pada Tabel 2 di bawah ini.

Tabel 2. Perbandingan Metode

\begin{tabular}{lllll}
\hline & Perusahaan & EOQ & POQ & Min-Max \\
\hline Q & 300 & 1183 & 1080 & 3185 \\
TIC & 521.155. & 245.404. & 248.841. & 385.125. \\
& 814 & 781 & 552 & 784 \\
F & 52 & 11 & 12 & 4 \\
SS & 5000 & 14,1 & 14,1 & 52 \\
ROP & 3254 & 3254 & 3289 \\
\hline
\end{tabular}

Analisa yang diperoleh dari penghitungan ketiga metode adalah kebijakan perusahaan yang digunakan saat ini adalah kuantitas pesan perusahaan sebanyak 300 unit dengan time frame per minggu dapat diakumulasi ke dalam kuantitas 1192 unit apabila kesepakatan kuantitas sekali pesan dengan vendor dapat diubah. Metode EOQ dan POQ memiliki jumlah frekuensi yang hampir sama dengan kuantitas pesan sebanyak 1192 untuk EOQ dan 1096 untuk POQ. Time frame yang digunakan dalam metode $E O Q$ dan $P O Q$ adalah bulan. Batasan untuk kuantitas pengiriman tidak dapat disamakan dengan batasan kapasitas gudang karena masing - masing memiliki kondisi yang berbeda.

Tabel 2 di atas menunjukkan perbandingan antara ketiga metode yang berisi total biaya persediaan, frekuensi pembelian dalam satu tahun, safety stock, dan juga angka ROP. Perhitungan tersebut menunjukkan metode EOQ memiliki total biaya persediaan yang paling rendah dibandingkan dengan metode $\mathrm{POQ}$ dan metode min - max. Meskipun begitu, tingkat service level yang digunakan dalam penghitungan ini adalah sebesar $80 \%$ yang mana masih dapat ditingkatkan guna mencapai customer satisfaction yang lebih tinggi.

Ketiga metode yang terlibat dalam laporan ini adalah EOQ dengan dasar pola pemesanan perusahaan yang memenuhi kondisi - kondisi asumsi dari metode EOQ. Selain itu penggunaan metode $\mathrm{POQ}$ adalah upaya membandingkan kebijakan perusahaan yang saat ini diterapkan guna dengan harapan dapat mengurangi safety stock yang ada. Selain itu, sesuai dengan cita cita perusahaan induk yang berkeinginan untuk mengubah pola push model menjadi pull model. Strategi push model dan pull model dilakukan dalam aktivitas supply chain yang bertujuan untuk mengatur pola distribusi produk. Supply chain adalah koordinasi strategis dari rantai pasokan dengan tujuan mengintegrasikan manajemen penawaran dan permintaan [10]. Sistem dorong (push) dan tarik (pull) dalam bisnis menjelaskan pergerakan suatu produk atau informasi antara dua subjek [11]. Terdapat tiga strategi manajemen supply chain yakni push model, pull model, dan push-pull model. Masing - masing model diterapkan sesuai dengan kondisi serta kebutuhan perusahaan. Push model adalah pola penyimpanan dengan cara memasok gudang dengan kapasitas tertentu agar gudang tersebut selalu maksimal dikarenakan permintaan konsumen tidak diketahui secara pasti. 


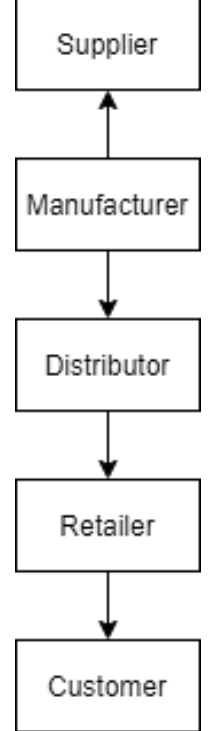

Gambar 8. Push Model

Model ini disebut juga sebagai build-to-stock yang mana JIP atau Jadwal Induk Produksi disusun berdasarkan peramalan atau peramalan permintaan produk terbaik (best guess) [12]. Pull model adalah model yang menggunakan gudang sebagai distribution centre yang menampung permintaan customer sehingga plant mengirim ke gudang sesuai dengan jumlah pesanan yang diminta tanpa harus memastikan gudang berada dalam kondisi yang harus selalu maksimal. Pull model dianggap menjadi model ideal dikarenakan model ini memungkinkan untuk menerapkan sistem zero inventories sehingga biaya penyimpanan tidak diperlukan [13]. Pada pull model, jumlah permintaan konsumen dapat diketahui secara pasti. Namun demikian, konsumen diharuskan untuk menunggu selama proses produksi berlangsung.

Model push-pull merupakan kombinasi antara model push dan model pull. Hal ini dapat menjadi pertimbangan dikarenakan model pull seringkali tidak memungkinkan untuk diterapkan secara keseluruhan pada suatu sistem produksi. Pada model push-pull, produk yang memiliki kesamaan akan diproduksi secara massal, untuk selanjutnya produk dengan spesifikasi akan diproduksi setelah adanya permintaan sehingga waktu tunggu produksi semakin pendek dan biaya inventori tetap kecil.

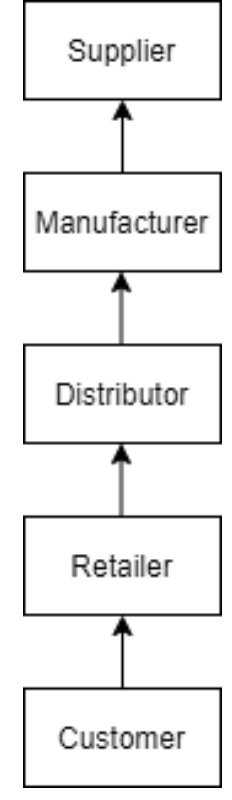

Gambar 9. Pull Model

Metode min - max digunakan sebagai pembanding dalam perhitungan dikarenakan metode ini adalah metode yang paling sering digunakan dalam operasional gudang di berbagai perusahaan. Sehingga berdasarkan analisa dari ketiga metode, metode yang cocok untuk diterapkan oleh perusahaan adalah metode $E O Q$ dikarenakan sesuai dengan kondisi - kondisi yang ada di perusahaan, selain itu metode EOQ menghasilkan analisa biaya yang paling rendah dari ketiga metode yang dibandingkan.

\section{KESIMPULAN}

Hasil perhitungan menggunakan ketiga metode yakni metode EOQ, metode POQ dan metode Min - Max menunjukkan bahwa total biaya persediaan paling rendah adalah perhitungan dengan metode EOQ. Hal ini dipengaruhi oleh besarnya kuantitas sekali pesan dan frekuensi pemesanan dalam satu tahun yang jauh di bawah angka perusahaan. Kuantitas ini dapat berbenturan dengan constraints dari vendor yang dinyatakan oleh perusahaan sebesar 300 ton, namun dalam perhitungan ini constraint tersebut diabaikan. Angka Reorder Point (ROP) dalam penghitungan metode $E O Q$ dan $P O Q$ berada di bawah kapasitas gudang, sehingga metode ini tidak berbenturan dengan kapasitas. Angka ROP pada metode min - max yang melebihi kapasitas gudang menunjukkan bahwa angka service level yang digunakan dalam perhitungan terlalu tinggi. Service level yang digunakan sebesar $80 \%$ memerlukan stok persediaan yang melebihi 
kapasitas gudang sehingga dapat dikatakan bahwa service level perusahaan masih di bawah $80 \%$ untuk metode $\min -\max$.

Service level berpengaruh besar dalam penentuan ROP yang memiliki batasan kapasitas gudang. Hal ini terlihat dari alternatif perhitungan yang diberikan apabila perusahaan ingin meningkatkan service level dari $80 \%$ menjadi $95 \%$, yakni tingkat ROP yang berada di atas kapasitas gudang. Isu yang muncul adalah peningkatan kapasitas gudang untuk menjangkau lebih banyak permintaan, atau bisa jadi dengan kapasitas 3400 itu utilitasnya belum maksimal. Namun dengan asumsi utilitas gudang sudah maksimal, maka kemungkinan ruang yang dipakai lebih dari 3400 sesuai dengan informasi yang disampaikan bahwa terdapat ruang - ruang kosong di luar gudang yang dipakai untuk penyimpanan kertas roll.

\section{REFERENSI}

[1] A. Amenan dan E. Fitriani, "PT SI Kuasai 55,8\% Pangsa Pasar Semen Indonesia," 8 Februari 2019. [Online]. Available: https://investor.id/business/pt-si-kuasai-558pangsa-pasar-semen-indonesia. [Diakses 10 Oktober 2019].

[2] P. A. S. Fithri, "Pengendalian Persediaan Pozzolan di PT. Semen Padang," Jurnal Optimasi Sistem Industri Vol.13, 2014.

[3] G. E. Alynardiana dan M. Saifi, "Analisis Perencanaan Persediaan Bahan Baku Menggunakan Metode EOQ," Jurnal Administrasi Bisnis, vol. 49, p. 17, 2017.

[4] A. Mail, M. Asri, A. Padhil, A. Takdir dan N. Chairani, "Pengendalian Persediaan Bahan Baku menggunakan Metode Min-Max Stock di PT. Panca Usaha Palopo Plywood," Journal of Industrial Engineering Management, pp. 9-14, 2018.

[5] I. Gani dan M. Saputri, "Analisis Peramalan dan Pengendalian Persediaan Bahan Baku dengan Metode EOQ pada Optimalisasi Kayu di Perusahaan Purezento," $e$ Proceeding of Management, vol. 2, pp. 2029 - 2041, Agustus 2015.

[6] C. Rizky, Y. Sudarso dan S. Sadriatwati, "Analisis Perbandingan Metode EOQ, Metode $\mathrm{POQ}$, dengan metode Metode MinMax dalam Pengendalian Persediaan Bahan Baku Pada PT Sidomuncul Pupuk Nusantara," Admisi dan Bisnis, vol. 16, pp. 11 - 22, 2016.
[7] Y. Evitha dan F. M. HS, "Pengaruh Penerapan Metode Economic Order Quantity (EOQ) Terhadap Pengendalian Persediaan Bahan Baku Produksi di PT. Omron Manufacturing of Indonesia," Jurnal Logistik Indonesia, vol. 3, pp. 88-100, 2019.

[8] Y.-L. Chang, WinQSB, New York: John Wiley \& Sons, 2003.

[9] Hadiguna, Dr. Rika Ampuh, Sistem Logistik, Padang: Andalas University Press, 2017.

[10] M. Arif, "Supply Chain Management," dalam Supply Chain Management, Yogyakarta, Deepublish, 2018, p. 44.

[11] M. Syaputra, "Penerapan Strategi Pemasaran Dorong dan Tarik dalam Keberlangsungan Pengelolaan Bisnis Rintisan PT. Compro Kotak Inovasi," Journal of Business \& Applied Management, vol. 12, 2019.

[12] K. C. Laudon dan J. P. Laudon, Management Information System, England: Pearson Education Limited, 2018.

[13] S. Sarbjit, "Study on Push/Pull Strategy Decision Taken by Organizations for Their Products and Services," Universal Journal of Management 5, vol. 5, p. 492, 2017.

\section{Complementary Subtitles:}

\section{Nomenklatur}

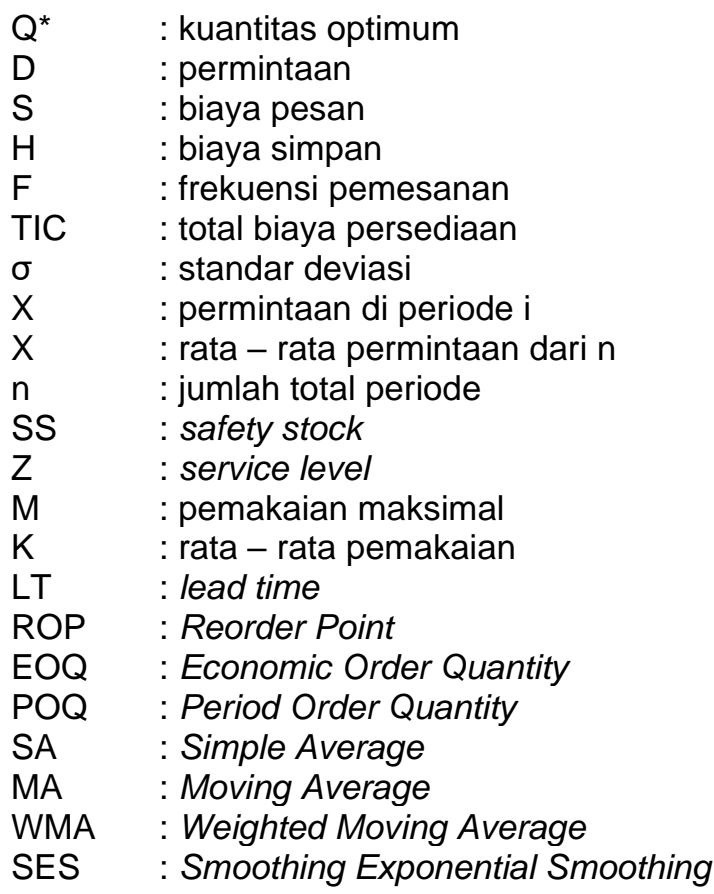




\section{Biografi Penulis}

\section{Zahra Zayyina Yustisia Arif.}

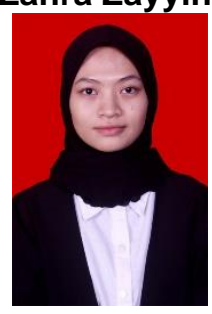

Lahir di Salatiga, Maret 1998. Saat

ini mahasiswa tingkat akhir pendidikan sarjana (S1) di Teknik Logistik Universitas Pertamina.

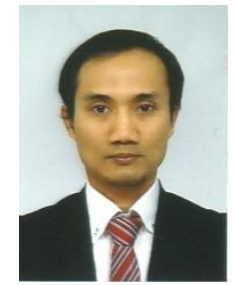

Dr. Eng. Iwan Sukarno, ST., M.Eng.

Lahir di Yogyakarta, * Agustus 1981. Riwayat pendidikan sarjana (S1) Teknik Industri, Universitas Andalas lulus tahun 2013, pendidikan Magister (S2) di Toyohashi University of Technology, Japan lulus tahun 2015 dan pendidikan doctor (S3) di Toyohasi University of Technology, Japan lulus tahun 2016 dalam bidang energy modeling. Saat ini pengajar di Jurusan Teknik Logistik Universitas Pertamina 2017-sekarang 